\title{
Adolescent and young adult perceptions of cancer survivor care and supportive programming
}

\author{
Karen Wasilewski-Masker, MD, MSc;ab Jordan Gilleland-Marchak, $\mathrm{PhD}$; ${ }^{\text {ab }}$ Kristen Vangile, \\ MPH; ${ }^{b}$ Brooke Cherven, RN, MPH; ${ }^{b}$ Amy Barry, RN, MSN; ${ }^{b}$ Amanda Masters, MPH;c \\ Jennifer Potter, MPH; ${ }^{d}$ Lillian Meacham, MD; $;{ }^{\mathrm{ab}}$ and Ann C Mertens, $\mathrm{PhD}^{\mathrm{ab}}$
}

${ }^{a}$ Emory University School of Medicine, b Aflac Cancer Center at Children's Healthcare of Atlanta, 'Council of State and Territorial

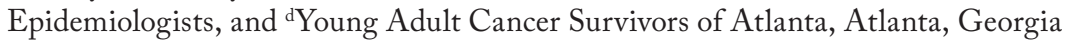

Background Improvements in cancer therapy have led to an increasing number of adolescent and young adult (AYA) survivors of childhood cancers. Many survivors have ongoing needs for support and information that are not being met.

Objective To conduct a program evaluation to identify AYAs' perceptions of survivor care services.

Methods Using a community-based approach, 157 AYA childhood cancer survivors (aged 15-30 years) completed a program evaluation survey to assess perceptions of the importance of survivor patient care services and supportive programming using a Likert scale (1, Not At All Important; 2, Of Little Importance; 3, Somewhat Important; 4, Important; 5, Very Important). Results Receipt of a medical summary was ranked as the most important survivor patient care service (mean, 4.5; SD, 0.91 ). $70 \%$ of respondents reported interest in late-effects education. Informational mailings were the most valued form of supportive programming and were endorsed by $62 \%$ of AYAs. Older survivors were more likely to value workshops $(P=.01-0.05)$, whereas those aged $19-22$ years valued weekend retreats $(P<.01)$ and social activities $(P<.01)$. Survivors of brain/CNS tumors were more likely to value social activities $(P=.03)$ and support groups $(P=.03)$, compared with leukemia survivors.

Limitations Contact information from the hospital tumor registry was used, which limited the number of correct addresses.

Conclusion The greatest care needs reported by AYA survivors of childhood cancer are services such as generation of a medical summary, late-effects education, and survivor-focused follow-up care, which are provided through cancer survivor programs. Development of additional programming to engage and further educate and encourage AYA survivors will be important to reinforce their adherence with survivor care throughout adulthood.

Funding/Sponsorship LiveStrong Community Based Participatory Research Planning Grant

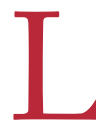

ong-term survival for pediatric cancer has improved to more than $80 \%$ in recent years because of improvements in cancer treatment. ${ }^{1}$ Decreased mortality among childhood cancer patients has resulted in a growing population of survivors who are at increased risk for health problems and early mortality, often in young adulthood., ${ }^{2,3}$ The needs of the young adult survivors of childhood cancer are unique; they face not only physical challenges but emotional, social, and financial hurdles in their transition from dependent child to independent adult and from pediatric- to adult-based care. ${ }^{4,5}$ The lack of an appropriate health care home for survivorship care after the transition from a pediatric institution to adult-based care is a national problem for many young adult survivors of childhood cancer in the United States. ${ }^{6}$ Access to survivorship care and support services for adolescent and young adults (AYAs) is essential but problematic because of the common transition-of-care issues such as lack of adult survivor care providers, geographic transitions, and general poor adherence with medical care in this age group. ${ }^{5}$

Over the last decade, pediatric oncology has led the way in forming cancer survivor programs (CSPs) with the goals of long-term follow-up (LTFU), early detection, and timely intervention for late effects; however, many pediatric programs can no longer care for patients after they reach a certain age. ${ }^{7,8}$ Once childhood cancer survivors reach young adulthood and transfer out of pediatric-based care, there is limited access to specialized survivor patient care and supportive programming. ${ }^{6,9}$ Thus, young adult survivors are often transferring to adult care while simul-

Accepted for publication December 7, 2015. Correspondence: Ann Mertens, PhD; amertens@emory.edu. Disclosures: The authors have no disclosures or conflicts of interest. JCSO 2016;14:291-298. (2016 Frontline Medical Communications. doi: 10.12788 /jicso.0228. 
taneously aging out of other community-based support programs and psychosocial services available to them in during adolescence (eg, camps, pediatric social events).

Survivorship care in adult oncology is emerging and often follows a disease-based model in which this young adult population does not usually fit. ${ }^{10,11} \mathrm{~A}$ recent survey of AYA cancer survivors found that more than half of survivors experienced unmet information and service needs related to their cancer treatment. ${ }^{12}$ Prominent organizations such as the Children's Oncology Group (COG), Institute of Medicine, National Cancer Institute, and LiveStrong have advocated that standards of care for LTFU of cancer survivors should include surveillance for late effects of cancer therapy, as well as medical and psychosocial interventions aimed to maximize health and quality of life across the lifespan. ${ }^{10,13-17}$ Despite the recommendations in the literature for life-long LTFU and supportive care, there are very limited resources for this growing population of young adult survivors who are no longer eligible for pediatric services, but are still living daily with the consequences of their childhood cancer experience medically, financially, socially, and psychologically.

Program evaluations are used to determine the effectiveness of current activities, and to assess whether these programs are fulfilling the needs of the population being targeted. The purpose of this project was to evaluate AYA survivors' perceptions of the importance of survivor patient care services and supportive programming. To accomplish that objective, we sought to gather feedback from current patients and former patients who had transferred to adultbased care. Given that a community-based approach has been advocated to inform, address, and ultimately decrease disparities for cancer care, ${ }^{18}$ clinical researchers at Emory University and Children's Healthcare of Atlanta (CHOA) partnered with community organizations to conduct a program evaluation and needs assessment of educational and support services for AYA cancer survivors. The results from the project were used to aid in the future planning of AYA patient care and support services at our institution and in our community.

\section{Methods}

\section{Patients and data collection}

Survivors of childhood cancer treated at $\mathrm{CHOA}$ were identified through the tumor registry of the Aflac Cancer and Blood Disorders Center at CHOA. At our institution, childhood cancer survivors typically transfer to adult-based care between the ages of 19-21 years. Contact information from the registry was cross-referenced with mailing lists from 2 community organizations that provide educational and support services for cancer survivors and their parents (Camp Sunshine and CURE Childhood Cancer, both in Atlanta, Georgia) to obtain the most up-to-date information. A total of 1,445 survivors aged 15-30 years and who had been diagnosed with cancer at age 20 years or younger, were identified as eligible. A contact address was available for 1,309 survivors. Survivors received 1 mailing that included the needs assessment survey, educational material about the need for survivorship care, services available for AYA survivors provided by various community organizations, and a stamped, addressed envelope to return the survey. Participants were also given the URL for a website where they could complete the survey online. To optimize honest responses by survivors, no identifying information was collected on returned surveys; therefore no subsequent mailings were possible. A total of 322 (24.6\%) survivors were known to have been lost to follow-up, based on mailed envelopes that were returned as undeliverable. A total of 157 needs assessment surveys were returned. This study was reviewed by the CHOA Institutional Review Board and approved as a program evaluation whereby consent was deemed not required.

\section{Survey design}

The needs assessment survey requested basic demographic information (gender, year of birth, primary cancer diagnosis, and age at diagnosis), and no personal health information was requested. Questions asked participants to rate the importance of supportive programming for AYA survivors and of survivorship patient care services, using a Likert scale (1, Not Important At All; 2, Of Little Importance; 3, Somewhat Important; 4, Important; 5, Very Important).

Participants were also asked to circle all topics of interest to them for educational workshops or mailings. The items posed in the survey were developed by a multidisciplinary consortium of clinical providers specializing in AYA survivorship care, leaders of community organizations with an interest in AYA services and programming, and AYA survivors. Survey options for programming were based on services that were available through the community organizations for younger populations (support group, counseling, activities), and novel, feasible services with possible appeal to young adults, based on input from young adult survivors themselves. The full survey can be found in Appendix 1 .

\section{Data analysis}

We used IBM SPSS Statistics (version 21) to complete data analyses, and $P$ values $\leq .05$ were considered statistically significant. Descriptive statistics were used to characterize the patient sample and overall survey responses. For the purposes of analyses, survivors' perceptions of the importance of supportive programming and survivorship patient care services were dichotomized as Important and Very Important versus Somewhat Important, Of Little Importance, and Not Important At All. Cochran's Q test statistics with Bonferroni corrections were used to compare survivors' perceived importance of different supportive programming activities. In addition, univariate logistic regression analyses were used to 
evaluate predictors of survivors' perceived importance of different supportive programming activities.

\section{Results}

The participants were an average age of 21.5 years (range, 15-30 years) at the time of survey completion, 12.7 years (range, 2-27 years) from diagnosis, and 46.5\% were male (Table 1). The mean age of diagnosis was 8.7 years. Selfreported participants' medical history included the following: 35.0\% leukemia diagnoses (acute lymphocytic leukemia [ALL], acute myeloid leukemia, [AML]), 15.9\% lymphoma diagnoses, $14.0 \%$ brain and CNS tumors diagnoses, $17.8 \%$ non-CNS solid tumor diagnoses (eg, neuroblastoma, sarcomas, Wilms tumor), and $16.6 \%$ other malignancies.

TABLE 1 Participant characteristics

\begin{tabular}{ll} 
Characteristic & $\begin{array}{c}\text { No. of } \\
\text { respondents (\%) } \\
(\mathbf{N}=\mathbf{1 5 7})^{\mathbf{a}}\end{array}$ \\
Sex & $73(46.5)$ \\
Men & $84(53.5)$ \\
Women & \\
\hline Age at survey, y & \\
(mean, 21.5; SD, 3.80) & $35(22.3)$ \\
$15-18$ & $63(40.1)$ \\
$19-22$ & $42(26.8)$ \\
$23-26$ & $17(10.8)$ \\
$27-30$ &
\end{tabular}

$\begin{array}{ll}\begin{array}{l}\text { Age at diagnosis, } y \\ \text { (mean, 8.7; SD, 5.53) }\end{array} \\ 0-4 & 50(31.8) \\ 5-9 & 31(19.7) \\ 10-14 & 47(29.9) \\ 15-21 & 28(17.8)\end{array}$

Time since diagnosis, $y$

(mean, 12.7; SD 6.24)

$\begin{array}{ll}2-5 & 22(14.0) \\ 6-10 & 40(25.5) \\ 11-15 & 46(29.3) \\ \geq 16 & 48(30.6) \\ \text { Primary diagnosis type } & \\ \text { Leukemia } & 55(35.0) \\ \text { Lymphoma } & 25(15.9) \\ \text { Brain/CNS tumors } & 22(14.0) \\ \text { Non-CNS solid tumors } & 28(17.8) \\ \text { Other malignancies } & 26(16.6)\end{array}$

'One respondent did not provide diagnostic information.

\section{Survivor perceptions of patient care services after cancer treatment}

The participants' opinions about the importance of 14 different survivor patient care services are shown in Table 2 . Receipt of an end-of-therapy medical summary was identified as the most important survivorship patient care service (on a scale of $1-5$ : mean, 4.5 ; SD, 0.91 ), with $87.8 \%$ of respondents indicating this was Important or Very Important (Table 2). More than $75 \%$ of respondents rated the following services as Important or Very Important:

- Being kept up to date with the latest treatments and LTFU information for survivors (mean, 4.3; SD, 0.93),

- Having primary care providers who understand survivor needs (mean, 4.1; SD, 1.16),

- Receiving LTFU care in a survivor program (mean, 4.2; $\mathrm{SD}, 1.08)$, and

- Getting information about reproductive risks/issues (mean, 4.0; SD, 1.23).

Receiving counseling for anxiety, depression, uncertainty, or fear of cancer recurrence (mean, 3.4; SD, 1.36) was rated lowest in importance; however, almost half of respondents found this to be Important or Very Important (49.7\%).

\section{Survivor perceptions of supportive programming after cancer treatment}

Within the context of possible topics of interest within informational workshops, 70\% of respondents were interested in being educated about late effects of treatment. At least half of respondents wanted to learn about health insurance (58.0\%), fertility (54.8\%), healthy lifestyle and exercise (53.5\%), and school or employment (50.3\%). Fewer survivors were interested in the topics of cancer advocacy (35.0\%) or dating and intimacy (31.2\%).

AYA survivors' beliefs about the importance of 6 types of supportive care programming are summarized and compared in Table 3. Informational mailings (62.1\%) were the most valued form of programming and endorsed as Important or Very Important significantly more often than were informational workshops, social activities, individual counseling, and support groups. Weekend retreats (56.7\%) were the next most valued type of programming and endorsed as Important or Very Important significantly more often than social activities or support groups. Informational workshops (49.4\%), monthly social activities (40.8\%), and individual counseling with an AYA specialist $(38.5 \%)$ were each endorsed as Important or Very Important significantly more often than monthly support groups (24.2\%).

Univariate logistic regression analyses showed no differences between men and women in their perceived importance of the 6 different supportive programming activities. The univariate logistic regression predictors of perceived importance of survivor supportive programming are displayed in Table 4. Compared with adolescents (15-18 
TABLE 2 Perceived importance of survivor patient care services

\section{AYA survivor patient care service}

Medical summary describing cancer history, late effects risks, monitoring plan

Being kept up-to-date with the latest treatment and LTFU information

\section{Having primary care providers who understand} the special needs of survivors

Receiving LTFU care at a cancer survivor program

Information about reproductive risks/issues

Dealing with long-term symptoms such as fatigue and pain

Information about keeping and/or getting health insurance

Opportunities to meet other cancer survivors

Participating in cancer survivorship studies and clinical trials

Receiving infertility treatment to increase chances of having children in the future
Assistance transitioning from an oncologist to a primary care provider
Opportunities to be socially active, including dating and meeting new friends

$$
\begin{aligned}
& \text { Help paying outstanding medical bills } \\
& \text { Counseling for anxiety, depression, } \\
& \text { uncertainty, or fear of cancer recurrence }
\end{aligned}
$$

Mean scorea (SD)

Rated Important or Very Important, n (\%)

$130 / 148$

(87.8)

$125 / 148$

(84.5)

$120 / 148$

(81.1)

$117 / 148$

(79.1)

$113 / 149$

(75.8)

$108 / 148$

(73.0)

$4.0(1.21)$

$108 / 148$

(73.0)

$93 / 149$

(62.4)

$88 / 149$

(59.1)

$85 / 147$

(57.8)

$3.6(1.47)$

84/147

(57.1)

$\begin{array}{cc}3.6(1.38) & 84 / 147 \\ & (57.1) \\ 3.6(1.35) & 82 / 148\end{array}$

(55.4)

$76 / 148$

(51.4)

$\begin{array}{cc}3.3(1.57) & 76 / 148 \\ & (51.4) \\ 3.4(1.36) & 74 / 149\end{array}$

(49.7)

AYA, adolescent and young adult

aBased on a Likert scale ranging from 1-5, where: 1, Not Important At All; 2, Of Little Importance; 3, Somewhat Important; 4, Important; 5, Very Important.

years), older survivor age groups were more likely to value informational workshops (19-22 years: odds ratio [OR], $2.48 ; P=.05 ; 23-26$ years: $\mathrm{OR}, 2.91 ; P=.03 ; 23-26$ years: OR, 5.76; $P<.01)$. In addition, transition-age young adults (19-22 years) were more likely value weekend retreats $(\mathrm{OR}$, $3.49 ; P<.01)$ and social activities (OR, $4.22 ; P<.01)$, compared with adolescents aged $15-18$ years. Survivors of brain and CNS tumors were more likely to value social activities (OR, 3.21; $P=.03$ ) and support groups (OR, 3.33; $P=.03$ ), compared with survivors of leukemia, whereas survivors of non-CNS tumors were less likely value weekend retreats (OR, 0.27; $P<.01)$ and social activities (OR, 0.33; $P=.05)$.

\section{Discussion}

Adolescent and young adult survivors of pediatric cancer are a vulnerable patient population that often does not receive consistent recommended surveillance and LTFU care through key transitions. ${ }^{19}$ By conducting program evaluations and needs assessments of educational and support services in this population, we can define disparities between what currently exists and what would be considered optimal care. This program evaluation project used a community-based approach to obtain insight into the needs of AYA survivors of childhood cancer, both from the perspective of medical patient care services, community supportive care services, and survivors themselves.

The key tenants of survivor care include regular LTFU guided by a comprehensive medical summary that includes a personalized risk assessment and surveillance recommendations based on the survivor's treatment history. The majority of AYAs in the present study believe that it is important to receive survivor-focused medical care through primary care providers who understand survivors' needs ( $81.1 \%$ of respondents) or at a cancer survivor pro- 
TABLE 3 Survivor supportive programming: comparison of perceived importance

\begin{tabular}{|c|c|c|c|c|c|c|}
\hline \multirow[b]{2}{*}{$\begin{array}{l}\text { AYA survivor supportive } \\
\text { programming }\end{array}$} & \multirow{2}{*}{$\begin{array}{c}\text { Rated Important or } \\
\text { Very Importanta } \\
\text { n (\%) }\end{array}$} & \multicolumn{5}{|c|}{ Comparison of perceived importance ${ }^{b}$} \\
\hline & & Mailings & Retreats & Workshops & $\begin{array}{c}\text { Social } \\
\text { activities }\end{array}$ & Counseling \\
\hline Weekend-long retreats & $\begin{array}{c}89 / 157 \\
(56.7)\end{array}$ & $\begin{array}{c}1.61 \\
(P=1.00)\end{array}$ & & & & \\
\hline $\begin{array}{l}\text { Monthly social activities } \\
\text { for survivors }\end{array}$ & $\begin{array}{c}64 / 157 \\
(40.8)\end{array}$ & $\begin{array}{c}4.69 \\
(P<.001)\end{array}$ & $\begin{array}{c}3.08 \\
(P=0.31)\end{array}$ & $\begin{array}{c}1.61 \\
(P=1.00)\end{array}$ & & \\
\hline $\begin{array}{l}\text { Individual counseling with } \\
\text { survivor specialist }\end{array}$ & $\begin{array}{c}60 / 156 \\
(38.5)\end{array}$ & $\begin{array}{c}-4.54 \\
(P<.001)\end{array}$ & $\begin{array}{c}-2.93 \\
(P=.051)\end{array}$ & $\begin{array}{c}-1.47 \\
(P=1.00)\end{array}$ & $\begin{array}{c}0.15 \\
(P=1.00)\end{array}$ & \\
\hline
\end{tabular}

AYA, adolescent and young adult

aBased on a Likert scale ranging from 1-5, where: 1, Not Important at All; 2, Of Little Importance; 3, Somewhat Important; 4, Important; 5, Very Important. bStandard Cochran's $Q$ test statistics with Bonferroni corrections were used to compare programming needs.

gram (79.1\%); however not all of them identify the value of receiving information on specific potential late effects of treatment. The literature indicates that an up-to-date medical summary is a critical tool for LTFU survivor care and essential in the transition from pediatric to adult-based care. ${ }^{20-22}$ Consistent with these opinions from the survivorship literature, AYA survivors in this study acknowledged having a medical summary as the most important patient care service. In the consensus statement by the American Academy of Pediatrics, American Academy of Family Physicians, and American College of Physicians, it is agreed that this medical document must be "portable and accessible." ${ }^{21}$ Cancer-specific tools such as the COG's Summary of Cancer Treatment, the American Society of Clinical Oncology's Treatment Summary, and the LiveStrong Care Plan have been developed as templates to create such a document after cancer treatment. It is important for AYAs to be aware of these valuable tools and even more important for them to be educated on how to advocate for themselves and their health care needs.

Results from this assessment demonstrated that patient care services provided through a cancer survivor program, including generation of a medical summary, late effects education, and survivor-focused follow-up care, were highly valued by AYA survivors. This study also emphasizes the need to develop and implement supportive care for young adult survivors of childhood cancer. In general, AYAs wanted to be kept up to date on information about the late effects of treatment but also revealed a preference for getting this information through informational mailings. This is a relatively inexpensive intervention that could reach a larger audience than retreats, support groups, or counseling, which were deemed significantly less important. Examples of other potentially successful education strategies to enhance the annual education given in a survivor clinic visit include providing online educational information and continuing to partner with community organizations to offer education (ie, survivor articles in quarterly newsletter, education at survivor camps and community events).

It is also notable that perceptions of supportive programming varied significantly between age groups and diagnosis types in this study. Though AYA survivors are often grouped together, these differences should be noted and explored when developing supportive care services and education interventions. This is particularly true for age, as there are significant developmental differences (physically, mentally, and socially), within this AYA population. For example, survivors aged 19-22 years considered weekend-long retreats and social activities to be more important than did adolescent survivors aged $15-18$ years. This may be because the older survivors had previously participated in social opportunities available to them through camps and local philanthropies during adolescence and they are no longer available to them after high school. As this transitional point can be a difficult time from a psychosocial perspective, identifying funding to develop supportive services such as camps, retreats, and social outings may help ease this transition for survivors.

Older participants in each young adult group reported a higher importance for informational workshops than did adolescents aged 15-18 years, which may reflect a 


\section{Original Report}

\begin{tabular}{|c|c|c|c|c|c|c|}
\hline \multirow{2}{*}{ TABLE 4 Survivor s } & \multicolumn{2}{|c|}{ Informational mailing } & \multicolumn{2}{|c|}{ Weekend retreat } & \multicolumn{2}{|c|}{ Informational workshop } \\
\hline & OR $(95 \% \mathrm{Cl})$ & $\boldsymbol{P}$ & OR $(95 \% \mathrm{Cl})$ & $\mathbf{P}$ & OR $(95 \% \mathrm{Cl})$ & $\mathbf{P}$ \\
\hline \multicolumn{7}{|l|}{ Current age, $y$} \\
\hline $15-18$ & $\begin{array}{c}1.0 \\
\text { (Referent) }\end{array}$ & - & $\begin{array}{c}1.0 \\
\text { (Referent) }\end{array}$ & - & $\begin{array}{c}1.0 \\
\text { (Referent) }\end{array}$ & - \\
\hline $19-22$ & $\begin{array}{c}1.54 \\
(0.63-3.77)\end{array}$ & .34 & $\begin{array}{c}3.49 \\
(1.46-8.36)\end{array}$ & $<.01$ & $\begin{array}{c}2.48 \\
(1.02-6.02)\end{array}$ & .05 \\
\hline $23-26$ & $\begin{array}{c}1.52 \\
(0.58-3.95)\end{array}$ & .39 & $\begin{array}{c}0.81 \\
(0.33-2.00)\end{array}$ & .64 & $\begin{array}{c}2.91 \\
(1.12-7.56)\end{array}$ & .03 \\
\hline $27-30$ & $\begin{array}{c}1.93 \\
(0.53-6.91)\end{array}$ & .32 & $\begin{array}{c}1.34 \\
(0.42-4.27)\end{array}$ & .63 & $\begin{array}{c}5.76 \\
(1.61-20.7)\end{array}$ & $<.01$ \\
\hline \multicolumn{7}{|l|}{ Diagnosis type } \\
\hline Leukemia & $\begin{array}{c}1.0 \\
\text { (Referent) }\end{array}$ & - & $\begin{array}{c}1.0 \\
\text { (Referent) }\end{array}$ & - & $\begin{array}{c}1.0 \\
\text { (Referent) }\end{array}$ & - \\
\hline Lymphoma & $\begin{array}{c}0.79 \\
(0.28-2.16)\end{array}$ & .63 & $\begin{array}{c}0.45 \\
(0.17-1.18)\end{array}$ & .10 & $\begin{array}{c}0.73 \\
(0.28-1.89)\end{array}$ & .52 \\
\hline $\begin{array}{l}\text { Non-CNS } \\
\text { solid tumor }\end{array}$ & $\begin{array}{c}0.50 \\
(0.19-1.31)\end{array}$ & .16 & $\begin{array}{c}0.27 \\
(0.10-0.70)\end{array}$ & $<.01$ & $\begin{array}{c}0.70 \\
(0.28-1.75)\end{array}$ & .44 \\
\hline $\begin{array}{l}\text { Brain/CNS } \\
\text { tumor }\end{array}$ & $\begin{array}{c}0.86 \\
(0.29-2.57)\end{array}$ & .78 & $\begin{array}{c}0.85 \\
(0.30-2.40)\end{array}$ & .76 & $\begin{array}{c}1.63 \\
(0.59-4.50)\end{array}$ & .35 \\
\hline \multirow[t]{3}{*}{ Other } & $\begin{array}{c}0.89 \\
(0.33-2.42)\end{array}$ & .82 & $\begin{array}{c}0.78 \\
(0.30-2.05)\end{array}$ & .61 & $\begin{array}{c}0.68 \\
(0.27-1.75)\end{array}$ & .43 \\
\hline & \multicolumn{2}{|c|}{ Social activities } & \multicolumn{2}{|c|}{ Individual counseling } & \multicolumn{2}{|c|}{ Support groups } \\
\hline & OR $(95 \% \mathrm{Cl})$ & $\boldsymbol{P}$ & OR $(95 \% \mathrm{Cl})$ & $\boldsymbol{P}$ & OR $(95 \% \mathrm{Cl})$ & $\boldsymbol{P}$ \\
\hline \multicolumn{7}{|l|}{ Current age, $y$} \\
\hline $15-18$ & $\begin{array}{c}1.0 \\
\text { (Referent) }\end{array}$ & - & $\begin{array}{c}1.0 \\
\text { (Referent) }\end{array}$ & - & $\begin{array}{c}1.0 \\
\text { (Referent) }\end{array}$ & - \\
\hline $19-22$ & $\begin{array}{c}4.22 \\
(1.66-10.7)\end{array}$ & $<.01$ & $\begin{array}{c}2.23 \\
(0.90-5.53)\end{array}$ & .08 & $\begin{array}{c}2.79 \\
0.94-8.26)\end{array}$ & .06 \\
\hline $23-26$ & $\begin{array}{c}1.51 \\
(0.54-4.22)\end{array}$ & .43 & $\begin{array}{c}1.61 \\
(0.60-4.30)\end{array}$ & .34 & $\begin{array}{c}1.20 \\
(0.34-4.17)\end{array}$ & .77 \\
\hline $27-30$ & $\begin{array}{c}3.00 \\
(0.87-10.3)\end{array}$ & .08 & $\begin{array}{c}3.25 \\
(0.96-11.0)\end{array}$ & .06 & $\begin{array}{c}3.27 \\
(0.83-12.9)\end{array}$ & .09 \\
\hline \multicolumn{7}{|l|}{ Diagnosis type } \\
\hline Leukemia & $\begin{array}{c}1.0 \\
\text { (Referent) }\end{array}$ & - & $\begin{array}{c}1.0 \\
\text { (Referent) }\end{array}$ & - & $\begin{array}{c}1.0 \\
\text { (Referent) }\end{array}$ & - \\
\hline Lymphoma & $\begin{array}{c}1.00 \\
(0.38-2.63)\end{array}$ & 1.00 & $\begin{array}{c}0.40 \\
(0.14-1.16)\end{array}$ & .09 & $\begin{array}{c}1.26 \\
(0.41-3.91)\end{array}$ & .69 \\
\hline $\begin{array}{l}\text { Non-CNS } \\
\text { solid tumor }\end{array}$ & $\begin{array}{c}0.33 \\
(0.11-0.99)\end{array}$ & .05 & $\begin{array}{c}0.48 \\
(0.18-1.28)\end{array}$ & .14 & $\begin{array}{c}0.67 \\
(0.19-2.32)\end{array}$ & .52 \\
\hline $\begin{array}{l}\text { Brain/CNS } \\
\text { tumor }\end{array}$ & $\begin{array}{c}3.21 \\
(1.13-9.16)\end{array}$ & .03 & $\begin{array}{c}1.00 \\
(0.37-2.70)\end{array}$ & 1.00 & $\begin{array}{c}3.33 \\
(1.15-9.70)\end{array}$ & .03 \\
\hline Other & $\begin{array}{c}1.29 \\
(0.50-3.30)\end{array}$ & .60 & $\begin{array}{c}0.88 \\
(0.34-2.26)\end{array}$ & .79 & $\begin{array}{c}1.47 \\
(0.50-4.38)\end{array}$ & .49 \\
\hline
\end{tabular}

need for survivorship-specific medical knowledge as survivors mature, rely less on their parents to manage their health, and embark upon significant decisions with regard to careers, marriage, and family. Compared with survivors of leukemia, survivors of brain and CNS tumors considered social activities and monthly support groups to be more 
important, whereas survivors of non-CNS solid tumors considered weekend retreats and monthly support groups to be less important. These differences may be indicative of the poorer social outcomes observed among adult survivors of childhood CNS cancers. ${ }^{23}$

There are several limitations to this study. First, the survey was mailed to patients fitting eligibility criteria identified from the tumor registry in which contact information may not be correct. Of the 1,309 surveys mailed, 322 $(24.5 \%)$ were returned as undeliverable, and there may have been more incorrect addresses we are not aware of if the letter was not returned by the post office. Therefore, the lost-to-follow-up rate is high. However, there was a $16 \%$ response rate (157 of 987) for this needs assessment. That suggests a highly motivated group of respondents, which is important in program evaluation and needs assessment research, but may not be representative of the total patient population.

Second, because the survey was designed to be anonymous, limited demographic data was collected. Therefore, responses could not be linked to those who had a previous evaluation in the cancer survivor program, and the data could not be analyzed for possible covariates or mitigating factors such as insurance coverage, ethnicity, education, marital status, or severity or type of cancer treatment. This survey also did not ask who had previously attended such educational/support services, suggesting a possible response bias on how survivors answered questions on the usefulness of each service. Additional research is also needed to explore these factors within a larger sample to determine generalizability to survivor patient care and supportive programming needs.

Future program development efforts should focus on optimizing education and access to care among AYA survivors. This can be achieved by increasing access to survivorship services for young adults with knowledgeable and willing primary care providers in partnership with pediatric oncology centers and adult cancer centers. The optimal model will likely require a variety of opportunities and depend on the individual patient as well as available services in their area. Essential to any model will be communication and education of both providers and survivors on the potential health problems facing AYA survivors after cancer therapy through a survivorship medical summary. ${ }^{24}$ Developing mechanisms to ensure portability of this care plan and the ability to update the plan are important to AYA survivors who experience many transitions in their health care. Several initiatives are underway to ensure access to key documents for survivors and providers including Cancer SurvivorLink, a patient-controlled web-based system that allows survivors to store their key health documents electronically and access them at any time from anywhere and also share them electronically with health care providers who are registered on (www. CancerSurvivorLink.org). 25,26 Communication regarding care can then be readily shared by the survivor with all relevant health care providers, assuring that seamless, proactive, evidence-based care is delivered to optimize health and quality of life.

\section{Conclusions}

Assessing the needs of AYA survivors of childhood cancer is an important first step in informing the allocation of resources to best serve this population and to create a more optimal model of comprehensive care in the transition from pediatric care to adult-based follow-up. This study demonstrates that AYA survivors of childhood cancer find the services traditionally provided through cancer survivor programs to be important. Perceived benefit to the cancer survivor is an essential part of most health behavior models. ${ }^{27}$ In the case of young adult survivors of childhood cancer, ongoing survivorship follow-up into adulthood would be considered a recommended health behavior due to the relatively high risk of treatmentrelated morbidity and mortality. ${ }^{2,3}$ Development of a variety of supportive programming that meets the needs of AYA and appeals to the various subgroups will be crucial in reinforcing their adherence with LFTU across the lifespan.

\section{Acknowledgments}

The authors acknowledge all participants in the AYA Consortium who made this project possible. In addition to the authors of this manuscript other participants included: Natia Esiashivili, MD (Department of Radiation Oncology, Emory University); Kathie McClure

(VoteHealthcare.org); Jill George, Kristin Connor, and Erin Hegeman (CURE Childhood Cancer); Melissa Hicks and Terri Sexton (Camp Sunshine and Emory University); Tracy Howk (Children's Healthcare of Atlanta), Daniel Zuniga (Georgia Institute of Technology), and Darren Johnson (CancerQuest).

\author{
References \\ 1. Ries L, Melbert D, Krapcho M, et al. SEER cancer statistics review, \\ 1975-2005. Bethesda, MD: National Cancer Institute; 2008. \\ 2. Mertens AC, Liu Q, Neglia JP, et al. Cause-specific late mortality \\ among 5-year survivors of childhood cancer: the Childhood Cancer \\ Survivor Study. J Natl Cancer Inst. 2008;100:1368-1379. \\ 3. Oeffinger KC, Mertens AC, Sklar CA, et al. Chronic health con- \\ ditions in adult survivors of childhood cancer. $\mathrm{N}$ Engl J Med. \\ 2006;355:1572-1582. \\ 4. Schwartz L, Tuchman L, Hobbie W, Ginsberg J. A social-ecological
}

model of readiness for transition to adult-oriented care for adolescents and young adults with chronic health conditions. Child Care Health Dev. 2011;37:883-895.

5. Freyer DR. Transition of care for young adult survivors of childhood and adolescent cancer: rationale and approaches. J Clin Oncol. 2010;28:4810-4818.

6. Henderson TO, Friedman DL, Meadows AT. Childhood cancer survivors: transition to adult-focused risk-based care. Pediatrics. 2010;126:129-136. 
7. Children's Oncology Group. Long-term follow-up guidelines for survivors of childhood, adolescent, and young adult cancers - version 4.0. http://www.survivorshipguidelines.org/. Released October 2013. Accessed July 1, 2016

8. Aziz NM, Oeffinger KC, Brooks S, Turoff AJ. Comprehensive longterm follow-up programs for pediatric cancer survivors. Cancer. 2006;107:841-848.

9. Casillas J, Kahn KL, Doose M, et al. Transitioning childhood cancer survivors to adult-centered healthcare: insights from parents, adolescent, and young adult survivors. Psychooncology. 2010;19:982-990.

10. Campbell MK, Tessaro I, Gellin M, et al. Adult cancer survivorship care: experiences from the LIVESTRONG centers of excellence network. J Cancer Surviv. 2011;5:271-282.

11. Hudson MM, Ness KK, Nolan VG, et al. Prospective medical assessment of adults surviving childhood cancer: study design, cohort characteristics, and feasibility of the St. Jude Lifetime Cohort study. Pediatr Blood Cancer. 2011;56:825-836.

12. Keegan TH, Lichtensztajn DY, Kato I, et al. Unmet adolescent and young adult cancer survivors information and service needs: a population-based cancer registry study. J Cancer Surviv. 2012;6:239-250.

13. Childhood cancer survivorship: improving care and quality of life. Washington, DC: National Academy Press; Institute of Medicine, 2003.

14. Hewitt M, Greenfield S, Stovall E. From cancer patient to cancer survivor: lost in transition. Washington, DC: National Academy Press; Institute of Medicine, 2005.

15. Landier W, Bhatia S, Eshelman DA, et al. Development of riskbased guidelines for pediatric cancer survivors: the Children's Oncology Group Long-Term Follow-Up Guidelines from the Children's Oncology Group Late Effects Committee and Nursing Discipline. J Clin Oncol. 2004;22:4979-4990.

16. Follow-up care after cancer treatment. Bethesda, MD: National Cancer Institute at National Institute of Health; 2010.

17. Closing the gap: research and care imperatives for adolescents and young adults with cancer. Bethesda, MD: US Department of Health and Human Services and Livestrong Young Adult Alliance, 2006.

18. Partridge E, Fouad M. Community-driven approaches for reducing health disparities in cancer. JAMA. 2010;303:1090-1091.

19. Oeffinger KC, Mertens AC, Hudson MM, et al. Health care of young adult survivors of childhood cancer: a report from the childhood cancer survivor study. Ann Family Med. 2004;2:61-70.

20. Hahn EE, Ganz PA. Survivorship programs and care plans in practice: variations on a theme. J Oncol Pract. 2011;7:70-5.

21. American Academy of Pediatrics, American Academy of Family Physicians, American College of Physicians-American Society of Internal Medicine. A consensus statement on health care transitions for young adults with special health care needs. Pediatrics. 2002;110(6 Pt 2):1304-1306.

22. Jacobs LA, Palmer SC, Schwartz LA, et al. Adult cancer survivorship: evolution, research, and planning care. CA Cancer J Clin. 2009;59:391-410.

23. Gurney JG, Krull KR, Kadan-Lottick N, et al. Social outcomes in the childhood cancer survivor study cohort. J Clin Oncol. 2009;27:2390-2395.

24. Meacham LR, Edwards P, Cherven B, et al. Primary care providers as partners in long-term follow-up of pediatric cancer survivors. J Cancer Surviv. 2012;6:270-277.

25. Williamson R, Meacham L, Cherven B, et al. Predictors of successful use of a web-based healthcare document storage and sharing system for pediatric cancer survivors: cancer SurvivorLink. J Cancer Surviv. 2014;8:355-363

26. Meacham LR, Williamson RS, Forehand RL, et al University Health Centers and Young Adult Survivors of Pediatric Cancer: changes in providers' familiarity with and practice of survivor care. J Adolesc Young Adult Oncol. 2014;3:12-19.

27. Rosenstock IM, Strecher VJ, Becker MH. Social learning theory and the Health Belief Model. Health Educ Q. 1988;15:175-183. 